\title{
Doing Less with More: Cohorts, Education and Civic Participation in America
}

Jonathan Horowitz

University of North Carolina-Chapel Hill

Keywords: higher education, cohorts, civic engagement, volunteering

Citation: This paper appears in Social Forces. Please use the following citation:

Horowitz, Jonathan. 2015. "Doing Less with More: Cohorts, Education, and Civic Participation in America." Social Forces 94:747-774.

Please direct correspondence to Jonathan Horowitz, Department of Sociology, CB \#3210, University of North Carolina, Chapel Hill, NC 27599 (jonathanhorowitzresearch@unc.edu). I am indebted to Neal Caren, Charles Seguin, Christopher S. Elliot, Mike Shanahan, Liz Kofman, Joe Bongiovi, Kenneth Andrews, Michelle Horowitz, Arne Kalleberg, the UNC Culture and Politics Workshop, and five anonymous reviewers for comments on an earlier draft of this paper. Additionally, I would like to thank Y. Claire Yang for feedback on my preliminary analyses. 


\begin{abstract}
Decades of social science research demonstrate the impact of education on civic participation. However, prior scholarship generally assumes that the returns to education do not change over time or geographic space. Absolute educational effects are not always plausible; as more individuals obtain a college degree, there are a greater number of qualified individuals competing for the same social resources. The present study tests the impact of education on civic participation, and whether this effect changes as the number of college-educated individuals increases over birth cohorts. The present findings suggest that in some cases, a college degree's impact on civic participation declines as more individuals obtain college degrees. The findings challenge commonly held assumptions about the effect of higher education on civic participation. Furthermore, the findings suggest that while sending an individual to college may increase civic participation, encouraging all high school students to go to college may undercut the benefits of college attendance.
\end{abstract}




\section{Doing Less with More: Cohorts, Education and Civic Participation in America}

To date, most sociological research indicates that educational attainment leads to more favorable life outcomes. A college education is associated with greater income, social network ties, prestige, cultural capital, racial tolerance, health, and psychological adjustment (Kingston et al. 2003; Pallas 2006; Hout 2012; Stevens, Armstrong, and Arum 2008). Of these, one of the most enduring associations is the relationship between education and civic participation (Putnam 1995; Verba, Schlozman, and Brady 1995; Converse 1972). Given that college completion has increased dramatically among recent birth cohorts, existing theory would predict a corresponding increase in civic participation.

However, civic participation has actually decreased instead of increased. Putnam (1995, 2000) argues that civic participation has declined over successive cohorts, even as educational attainment rose. Putnam’s argument is that the “Long Civic Generation”-born between 1910 and 1940 — is responsible for a disproportionate share of America’s face-to-face civic engagement. As the Long Civic Generation stops participating in local communities, bettereducated but less civically-oriented Baby Boomers and members of Generation X replace them. Thus, prior research suggests that the relationship between education and civic engagement is positive at the individual level of analysis, but negative when looking across cohorts.

So if college education has expanded so dramatically over successive cohorts, why are those same cohorts reporting less civic engagement? One approach suggests that education may not have a causal effect on civic participation since family background causes both educational attainment and civic participation (e.g., Schnittker and Behrman 2012). However, Nie, Junn, and Stehlik-Barry (1996) provide another solution: They argue that while education provides the human, social, and cultural capital to participate in civic life, there are only a fixed number of 
civic engagement opportunities (e.g., leadership positions in local organizations). When the entire population has the same resources, there is greater competition to become involved in each civic opportunity, making it harder for each individual with a college degree to participate. However, many civic participation opportunities are not competitive (Campbell 2009); for example, there is no upper limit to the number of people who can sign a petition. Furthermore, this theory is at odds with the consensus about the effects of education on other life outcomes (e.g., income), which suggests that the effect of education on behavior has remained constant or increased over time (Fischer and Hout 2006).

The aggregate trends suggest that as the proportion of individuals with a college degree in each cohort increases, the relationship between education and civic participation declines. However, to date there is little consensus whether this relationship holds at the individual level of analysis. Using the case of civic participation, the present study evaluates education's effects on social outcomes. When does education confer benefits regardless of the competition, and when are the returns to education devalued in highly-educated cohorts? The present study therefore investigates whether the effects of education on civic participation are due primarily to (a) absolute effects that remain constant depending on competition, (b) relative effects that change depending on the level of competition, or (c) selection effects that disappear as college education becomes uncoupled from other causes of civic participation.

\section{Absolute, Relative, and Selection Educational Effects}

Individuals who go to college participate more in civic life, and there are at least four reasons why education may increase civic participation. First, college experiences help strengthen human capital (Goldin and Katz 2008), increasing a graduate’s ability to perform civic acts (Wilson and Musick 1997). Second, college-educated individuals are able to obtain 
higher-paying and more secure jobs (Kalleberg 2011; Goldin and Katz 2008); they are less likely to need to work a second job and have more freedom to take time off of work, enabling them to spend more time participating in local organizations (Wilson and Musick 1997; Putnam 2000). Third, college promotes interpersonal interaction, increasing social capital ${ }^{\mathrm{i}}$ (Moffatt 1989; Stevens, Armstrong, and Arum 2008). Finally, colleges develop cultural capital—as well as confidence and social prestige — by providing a better understanding of how social institutions work (Stevens, Armstrong, and Arum 2008; Wilson and Musick 1997).

Educational attainment has expanded rapidly in more recent cohorts (Snyder and Dillow 2010), but Putnam (1995; 2000) demonstrates there has been a decline in face-to-face civic engagement over the same cohorts. Putnam's thesis was originally controversial, with critics arguing that some types of civic organizations are disappearing while others are taking their place (e.g, Ladd 1999). But where Putnam’s (1995) earlier work conflates associational membership with civic participation, his later publications (2000) show that there has been a cohort-level decline in civic behaviors that are not tied to a specific social interest (e.g., attending public meetings, writing letters to the newspaper, contacting senators and congresspersons, serving as a leader in an organization, signing petitions). Caren, Ghoshal, and Ribas (2011) also found cohort-level decreases in petition signing and protesting, although they found that the decline started with later cohorts. However, differences in voting behavior are primarily due to period rather than cohort changes (Smets and Neundorf 2014; Frenk, Yang, and Land 2013) When a cohort-level decline in civic participation occurs at the same time as a cohortlevel increase in educational attainment, it is reasonable to question whether the relationship has changed (Nie, Junn, and Stehlik-Barry 1996). However, most scholarship assumes an "absolute educational model" in which the value of a college degree does not change over time (Nie, Junn, 
and Stehlik-Barry 1996, 97-101; Converse 1972). According to the absolute educational model, coursework and extra-curricular programs enable the student to develop crucial network ties, understandings of how to behave in adult social life, skills such as public speaking and managing projects, and eventually higher-paying jobs (Stevens, Armstrong, and Arum 2008; Hout 2012). As more people in recent cohorts attend college, they will obtain more human, financial, social, and cultural capital; these forms of capital then increase a person's capacity to participate in civil society. Thus, the absolute educational model posits that the overall declines in civic participation are unrelated to a mass expansion in higher education, and due entirely to other cohort-level trends.

However, it is possible that the returns to educational degrees have changed and the relative value of education has decreased. Although a college degree may enable the student to develop skills and resources, a mass increase in these forms of capital creates "degree inflation" in social processes (Campbell 2009; Nie, Junn, and Stehlik-Barry 1996; Huang, van den Brink, and Groot 2009). For example, college experiences develop human, social, and cultural capital and thus can help an individual obtain a leadership position in a voluntary association, but only if earned capitals differentiate the individual from other potential candidates in his or her cohort (Tenn 2005).

Campbell (2009) argues that relative educational effects are most pronounced when there is intense competition for limited resources. For example, there should be a strong relative educational effect for leadership positions in organizations. If only one person in the organization has attended college, we would expect that this person would have greater social and cultural capital, which would ensure their ability to obtain the leadership position (see also: Wilson and Musick 1997). But if multiple individuals have attended college, then the various candidates will 
be competing against others with comparable advantages. In contrast, there is no competition necessary to sign a petition. The purpose of petition signing is to gather as many names as possible, and therefore the effects of education are more likely to remain constant across time. Relative educational effects may also occur via work opportunities. Until recently, a college graduate entering the labor market could expect to obtain a well-paid and secure job (Kalleberg 2011). Having a well-paid and secure position permits an individual to avoid working extra shifts or additional jobs, and also take time off to attend community events (Putnam 2000; Wilson and Musick 1997). Scholars have shown that individuals with insecure job histories and lower work autonomy participate less in civic life (Rotolo and Wilson 2003; Wilensky 1961; Wilson and Musick 1997), although the effect of insecure employment is most damaging during young adulthood (Elder 1999; Brand and Burgard 2008). But according to the relative educational hypothesis, as more people earn college degrees the competition for each individual job becomes more intense and individuals do not obtain labor market rewards commensurate with their educational experiences (see also: Vaisey 2006). Furthermore, the pool of high-paying and secure jobs started to decrease in the 1980s (Kalleberg 2011), stunting the career growth of college graduates born in the late 1950s and beyond. This would raise the costs of participation for younger cohorts, encouraging free-riding in civic life. Thus, there could be a relative impact of education on any civic act that requires substantial resources, such as attending public meetings or contacting a senator or congressperson.

Finally, education's impact on civic participation could be spurious because the relationship between education and civic participation may be confounded with prior family influences (Gibson 2001; Schnittker and Behrman 2012). The selection hypothesis suggests that adolescents with high levels of financial and cultural capital are more likely to attend college, 
and also to eventually perform civic acts. But there is an increasing emphasis on sending all students to college (Goyette 2008; Rosenbaum 2001), which means that fewer people who attend college are already equipped with the resources to participate in civic life. Since fewer people attending college have the resources to participate in civic life, sending more people to college weakens the observed relationship between education and civic participation. However, support for the selection hypothesis is mixed. While Huang, Maassen van den Brink, and Groot (2009) argue that the relationship between education and general social participation is inflated by selection mechanisms, their analysis also supports the relative education argument as an alternative explanation. Furthermore, although Kam and Palmer (2008) find that education is a proxy for pre-adult influences, their findings have been challenged by more recent scholarship (Henderson and Chatfield 2011; Mayer 2011). Finally, Brand (2010) finds that education's impact on civic participation is actually strongest for those who are least likely to attend college, suggesting a strong causal effect.

The absolute, relative, and selection educational hypotheses lead to different empirical predictions about the educational gap in civic participation. The absolute educational hypothesis predicts that the gap in civic participation will remain similar as cohorts become better educated. Meanwhile, the relative education hypothesis would predict that the participation gaps between those with a college background and those without a college background would shrink. In particular, the relative education hypothesis expects the rate of participation to drop among college-educated individuals, but not among those without a college degree. Furthermore, this drop should only occur for competitive civic activities. Finally, the selection effect hypothesis applies equally to both competitive and non-competitive civic life. Because competition is irrelevant to the selection effects hypothesis, this theory would predict that the gap between those 
with college degrees and those without college degrees should narrow across both competitive and non-competitive civic acts.

\section{Potential Confounding Effects}

Education is only one possible explanation for civic participation. Prior scholarship finds that living in the political south is also associated with lower levels of civic participation (Putnam 1995, 2000; Gomez and Gunderson 2003). Additionally, union membership increases civic participation, since unions provide social connections and civic opportunities (Kerrissey and Schofer 2013; Putnam 2000; Zullo 2013). Meanwhile, white individuals are much more likely to volunteer or participate in political activities than African-Americans and self-identified Hispanics (Verba, Schlozman, and Brady 1995; Musick and Wilson 2007), although this may be caused by differences in educational attainment. Meanwhile, women are more likely to volunteer than men (Musick and Wilson 2007), and middle-income individuals are also more likely to volunteer (Lee and Brudney 2009; McBride et al. 2011). Marriage may also affect civic participation by increasing social connectedness (Putnam 2000; Rotolo and Wilson 2006); however, Oesterle, Johnson, and Mortimer (2004) find no marriage effect and Stoker and Jennings (1995) suggest that individuals adjust their political participation to match that of their marital partner. Finally, job status may have an effect on civic participation; there is some evidence showing that unemployed individuals participate less in community affairs (Lim and Sander 2013), and some scholars posit that homemakers and part-time employees have more time to participate in civic life (Putnam 2000; Price 2002).

Prior scholarship generally accounts for alternative explanations at the individual level, but does not necessarily account for non-cohort temporal trends such as age and period effects. As Yang (2010) notes, period effects are historical events that affect everyone currently alive in a 
population; age effects affect everyone at a certain point in their lives, regardless of which historical era they live in; finally, cohort effects are historical forces that only impact individuals of a certain age. Unfortunately, age, period, and cohort effects are independent processes that occur at the same time. Since the relative educational hypothesis is primarily a cohort-level explanation (Tenn 2005), period and age effects may confound the education-civic participation relationship if omitted from the analysis.

For example, social issues may provoke civic engagement independent of cohort changes (Caren, Ghoshal, and Ribas 2011; Frenk, Yang, and Land 2013). Contentious issues are period effects that could generate an outpouring of letters to the editor, contacting elected officials, petition signing, and attendance at public meetings. Similarly, transformations in civic life and political advocacy may be period effects that would confound cohort-level explanations. For example, increasing internet-based behavior and protest behavior could lead to newer unmeasured civic acts such as boycotts, protests and email campaigns which substitute for older forms of civic participation (Skoric, Ying, and Ng 2009; Meyer and Tarrow 1998) ${ }^{\mathrm{iii}}$. Additionally, while Putnam (2000) posits that political culture in the political south is less conducive to civic participation, there may be period-based changes in regional political culture.

Research also suggests that aging impacts civic participation. Many researchers argue that young adults with kids are likely to be involved in their children's extra-curricular activities (Putnam 2000; Rotolo 2000). Older adults are also more likely to volunteer, due to higher levels of time and loss of prior social roles connected to work (Choi 2003; Kaskie et al. 2008; Putnam 2000). However, there is some evidence that individuals may perform less civic engagement as they age due to increasing health problems (Choi 2003; Gomez and Gunderson 2003). 
Finally, there are a few additional cohort trends which may complicate the relationship between education and civic engagement. Putnam (2000) argues that declining levels of civic participation are due to declines in informal social activities and social trust over cohorts; with a lack of social trust and connectedness, fewer individuals are willing to participate in civic life. Putnam also suggests that television watching habits may lead to a decrease in civic participation, although it is unclear whether this is a period or cohort effect. Additionally, the inconsistent relationship between marriage and civic participation may be due to a change in marital relationships across different cohorts. Thus, an analyst cannot assume that changes in education are the only reason for cohort-level changes in civic participation ${ }^{\mathrm{iv}}$.

Age and period effects are frequently conflated with cohort trends, and a failure to control for all three leaves the cohort analyst susceptible to omitted variable bias (Mason et al. 1973). Unfortunately, an effective cohort analysis generally requires repeated cross-sectional surveys or accelerated panel data, and also a method to control for all three effects simultaneously (Yang 2010). As a result, past scholarship on this topic rarely uses data and statistical methods that can separate cohort from age and period effects. For example, some scholars tend to use a single cross-sectional time point to estimate cohort effects (Campbell 2009; Nie, Junn, and Stehlik-Barry 1996), although this conflates both period and age with cohort differences. Other political scientists have datasets that span multiple time periods, but they also fail to control for both age and period effects (Helliwell and Putnam 2007; Tenn 2005).

\section{Data and Methods}

This study uses the Roper Social and Political Trends Data, an archive of 207 national polls conducted by in-home interviewers most months between 1973 and 1994 (Brady et al. 2000). The polls use a stratified probability sampling procedure to provide a representative 
sample of the non-institutionalized United States population; the Roper Organization also constructed weights to correct for under- and over-representation based on education, gender, income, and race. This data includes a large battery of questions that measure civic and political participation, and is arguably the most important source of data for Putnam's (2000) arguments in Bowling Alone.

I then account for age, period, and cohort trends in civic engagement with CrossClassified Random Effects Models (also known as CCREMS; Yang 2008; Frenk, Yang, and Land 2013; Yang 2006). Cross-Classified Random Effects Models are a special type of multilevel model where instead of nesting observations within a level-two grouping (e.g., school) each case is simultaneously nested within separate level-two groupings (e.g, period and cohort). Neither period nor cohort are nested inside the other, and thus the observations are "crossclassified"; the intercept is allowed to take on different values depending on whether the participant exists in a particular cohort or time period. If the model is identified by splitting age, period, and cohort into different time intervals, this produces a unique solution for each age, period, and cohort combination. Meanwhile, the analyst can allow individual-level predictors (or "level-one variables”) to also vary across different cohorts or periods.

\section{Data}

The Roper Social and Political Trends is an ideal data set to measure civic engagement over time because it includes an unparalleled number of questions about civic participation in the prior 12 months. This is particularly important because studies using different indicators of civic behavior show markedly different results (Helliwell and Putnam 2007; Nie, Junn, and StehlikBarry 1996; Caren, Ghoshal, and Ribas 2011; Campbell 2009). In this study, I use six different civic behaviors as dependent variables ${ }^{\mathrm{v}}$. These include whether the participant had written to 
their senator or congressperson ${ }^{\mathrm{vi}}$, wrote a letter to the newspaper, had a position of leadership in a local organization, signed a petition, attended a public meeting, or been a member of a group devoted to promoting better government (e.g., the League of Women Voters).

The other major advantage of the Roper data set is its unusually large size. The data set includes over 400,000 participants, and a total of 319,152 participants answered questions about their education and civic participation. Because age, period, and cohort are perfectly related, Age-Period-Cohort (APC) models are extremely data-intensive; this problem is compounded because civic behavior is a relatively rare event. The Roper Social and Political has several hundred thousand participants, and therefore it is possible to build stable Age-Period-Cohort (APC) models of a low base rate activity.

However, there are two major issues with using the Roper data to estimate changes in civic participation over time. The first problem is that the Roper data is missing a number of potentially useful variables, such as information about the participant's parental background or earlier life. Similarly, some constructs are operationalized in imprecise ways; for example, this dataset measures racial background with a simple three-category system (white, black, and “other”). The second issue is that the surveys failed to ask the respondents' age until 1978, and then the respondents' age is coded as a collapsed continuous variable in five-year increments. Fortunately, it is possible to estimate Age-Period-Cohort (APC) models using five year age intervals, omitting the median age category (40-44) to provide a facsimile of a centered age variable. In all analyses, I omit data points in the age categories 18-24 and over 65 . This is because the coding of these categories changes in the early 1990s, but the 18-24 age grouping also poses special problems for measuring educational attainment. The normative age for 
obtaining a 4-year degree is 22, and thus most of the people between 18-24 years old that will eventually complete a 4-year degree have not yet done so.

I list the summary statistics for the individual-level independent and dependent variables in Table 1. I measure college completion with a series of dummy variables, with individuals who have no college experience as the reference category. The other three categories are participants who have completed some college or have a 2-year degree ${ }^{\mathrm{vii}}$, those who have completed a 4-year undergraduate degree, and those who have completed at least some graduate education.

\section{TABLE 1 HERE}

I also construct a variable that measures the proportion of individuals in each cohort and region that possess a four-year college degree. At present, there is a scholarly disagreement about whether it is more important to compare a person's educational attainment to other individuals in their cohort or to others in their specific region. Tenn (2005) argues that individuals do not compete against others in different cohorts; individuals are age-stratified and therefore individuals of different cohorts occupy different social spaces at any given time (see: Riley 1987). On the other hand, Helliwell and Putnam (2007) are concerned that individuals only compete against each other locally; a person in Arkansas does not necessarily compete against an individual in California. Thus, Tenn (2005) measures relative education as cohort-specific educational attainment, while Helliwell and Putnam’s (2007) measurement includes different levels of educational attainment for each region. Thus, Tenn (2005) measures relative education as cohort-specific educational attainment, while Helliwell and Putnam’s (2007) measurement includes different levels of educational attainment for each region. To address both concerns, I calculate the relative education as the proportion of college-educated individuals per each combination of census division and five-year cohort. I use micro-data extracts of the Current 
Population Survey (King et al. 2010), and present the results in Figure $1^{\text {viii }}$ (King et al. 2010). All census regions show a similar trend-there is a large spike in the proportion of individuals with a four-year degree starting with the cohort of 1946-1950, and a second increase peaking with the 1971-1975 cohort.

FIGURE 1 HERE

I plot the six civic participation measures in this study over cohorts in Figure 2; the descriptive statistics show that while there was an increase in civic participation among those born in the early Baby Boom cohorts, this number has fallen rapidly since then. However, critics have suggested that this could be due to period effects; for example, some scholars argue that new forms of civic participation are replacing older civic acts. Fortunately, because the CCREMs can disentangle period and cohort effects (Caren, Ghoshal, and Ribas 2011; Yang 2008; Frenk, Yang, and Land 2013; Yang 2006), this modeling strategy can account for a large number of alternative explanations, especially those that affect all individuals regardless of cohort.

FIGURE 2 HERE

\section{Analytic Approach}

I use Cross-Classified Random Effects Models to analyze five-year birth cohorts, which is the standard categorization scheme in most cohort models (Yang 2008, 2010; Caren, Ghoshal, and Ribas 2011). Cross-Classified Random Effects Models (CCREMs) are more efficient than models that include cohort and period as fixed effects (Yang and Land 2008), and are usually the best choice for analyzing cohort trends in repeated cross-sectional data (Yang 2010). However, presenting all three time constructs (age, period, cohort) in five year intervals creates an identification problem, where age subtracted from period always equals cohort and creates a 
perfect linear dependency (Glenn 2003). To break the perfect linear dependence of age-periodcohort, I identify the model by presenting period in three-year groups instead of five-year sets.

The present analysis utilizes a generalized linear mixed model with a logit link function for each of the six dependent variables, and includes the weights constructed by the Roper organization. The first model (Basic Age-Period-Cohort) is a CCREM to show the cohort trends in civic participation. The Basic APC model omits all covariates aside from the intercept, age, and random intercepts for period and cohort; this model helps to clarify whether there is a substantial drop in civic participation and when it occurs, and provides a context for interpreting any changes in the education-civic participation relationship. This model is represented by the level-one equation:

$\operatorname{Logit}\{p($ participation $)\}=\beta_{0}+\beta_{1 j k}\left(X_{\text {age }}\right)+e_{i j k}$

And the level-two equation is:

$\beta_{0}=\gamma_{0_{-} 0}+t_{0 j}+c_{0 k}$

Where $\beta_{1 j k}$ represents the age contrast (compared to the median age category) per five year grouping, and $\beta_{0}$ represents the intercept. The intercept, in turn, is made up of the timeinvariant intercept $\left(\gamma_{0_{-} 0}\right)$, the period effect $\left(t_{0 j}\right)$, and the cohort effect $\left(c_{0 k}\right)$.

The second set of models (the "Relative Education Model") is a CCREM that tests whether the civic return from education decreases as the number of college-educated individuals increases. The level-one equation for the Relative Education Model is:

$$
\begin{aligned}
& \text { Logit }\{p(\text { participation })\}=\beta_{0}+\beta_{1 j k}\left(X_{\text {age }}\right)+\beta_{2 j k}\left(X_{\text {female }}\right)+\beta_{3 j k}\left(X_{\text {black }}\right)+\beta_{4 j k}\left(X_{\text {other }}\right)+ \\
& \beta_{5 j k}\left(X_{\text {other }}\right)+\beta_{6 j k}\left(X_{\text {married }}\right)+\beta_{7 j k}\left(X_{\text {kids } 12}\right)+\beta_{8 j k}\left(X_{\text {kidsover } 12}\right)+\beta_{9 j k}\left(X_{j o b s t a t u s}\right)+ \\
& \beta_{10 j k}\left(X_{\text {union }}\right)+\beta_{11 j k}\left(X_{\text {topincome }}\right)+\beta_{12 j k}\left(X_{\text {bottomincome }}\right)+\beta_{13 j k}\left(X_{\text {some_college }}\right)+ \\
& \beta_{14 j k}\left(X_{4 \_ \text {year_degree }}\right)+\beta_{15 j k}\left(X_{\text {more_than_four_year_degree }}\right)+\beta_{16 j k}\left(X_{\text {south }}\right)+e_{i j k}
\end{aligned}
$$


The level-two equations are represented by:

$$
\begin{aligned}
& \beta_{0}=\gamma_{0 \_0}+\gamma_{0 \_1}\left(X_{\text {college_proportion }}\right)+t_{0 j}+c_{0 k} \\
& \beta_{6 j k}=\gamma_{6 \_0}+c_{6 k} \\
& \beta_{13 j k}=\gamma_{13 \_0}+\gamma_{13_{-} 1}\left(X_{\text {College_proportion }}\right) \\
& \beta_{14 j k}=\gamma_{14 \_0}+\gamma_{14 \_1}\left(X_{\text {college_proportion }}\right) \\
& \beta_{15 j k}=\gamma_{15_{-} 0}+\gamma_{15_{-} 1}\left(X_{\text {college_proportion }}\right) \\
& \beta_{16 j k}=\gamma_{16 \_0}+t_{16 j}
\end{aligned}
$$

Where $\beta_{2 j k}$ represents the contrast between males and females, $\beta_{3 j k}$ and $\beta_{4 j k}$ represent the difference between non-white and white individuals, $\beta_{5 j k}$ represents the Hispanic selfidentification, $\beta_{6 j k}$ represents the contrast between those who are married and those who are not, while $\beta_{7 j k}$ and $\beta_{8 j k}$ represent whether the participant has younger and older children. Since there are differing results for the effect of marriage on civic participation, it is possible that there are cohort differences in marriage effects; therefore, I allow marriage status to vary across cohorts $\left(c_{6 k}\right)$. Meanwhile, $\beta_{9 j k}$ represents job status, $\beta_{10 j k}$ represents the contrast between those who are union members and those who are not, and $\beta_{11 j k}$ and $\beta_{12 j k}$ represent whether the participant is in the top or bottom income quartile. Educational attainment is measured by three separate dummy variables; those who have some college experience or a 2 year degree $\left(\beta_{6 j k}\right)$, those who have a four year college degree $\left(\beta_{7 j k}\right)$, and those who have education beyond a bachelor's degree ( $\beta_{8 j k}$ ). Additionally, $\beta_{9 j k}$ represents living in the American political south; since living in the political south may differ from year-to-year, I allow it to vary across periods $\left(t_{16 j}\right)$.

The most important portion of the model is the interaction between the cohort and geography-specific proportion of individuals with a four-year college degree $\left(\gamma_{01}\right)$ and $\left(\gamma_{6 \_1} ; \gamma_{7_{1} 1} ; \gamma_{8_{-} 1}\right)$. This portion of the model provides the most direct test of the relative education 
hypothesis. Based on prior research, we would expect a strong educational effect on civic participation $\left(\beta_{6 j k} ; \beta_{7 j k} ; \beta_{8 j k}\right)$. However, if the relative education hypothesis is true, then we would expect the relative education-participant education interaction to be statistically significant and negative; this would indicate that as the total amount in the population rises, the educational returns to civic participation declines.

I use PROC GLIMMIX in SAS 9.2 for all analyses. To judge the significance of cohort and period trends, I first use F-tests to assess whether there are cohort and period differences in civic participation (Frenk, Yang, and Land 2013), followed by graphing the effect sizes. In addition to re-examining the relative education hypothesis with the aggregated Roper, Princeton, and Saguaro Seminar datasets, I also tested to see whether my model was robust to an alternative coding of education. Thus, I replicated the analyses in this paper using a single dummy variable for education—whether the participant had completed a four-year degree. The predicted probabilities for these models are substantively similar to the findings presented here.

\section{Findings}

In this section, I present the results from the CCREM models. First, I present the results from each model. Table 2 contains the results from the basic APC model. I am able to reject the null hypothesis ${ }^{\mathrm{ix}}$ for cohort, and thus there are statistically significant differences in civic participation across cohort for all six dependent variables; however, I am unable to reject the null hypothesis for period.

\section{TABLE 2 HERE}

I present the cohort trends for performing different types of civic behaviors in Figure 3. Cohorts born between World War I and World War II are generally more likely to volunteer than those born after 1960. However, early Baby Boomers (1946-1955) are the most likely to take on 
organizational leadership roles, sign petitions, attend public meetings, and write letters to the newspaper. There is a noticeable drop with the late Baby Boom cohorts (1956-1965), with a continuing decline into Generation X. The patterns presented here generally support Putnam (2000); there has been a cohort-level decline in civic participation, although the decline started after the early Baby Boom cohorts (similar to the patterns shown by Caren, Ghoshal, and Ribas 2011).

\section{FIGURE 3 HERE}

Table 3 contains the results from the second set of models, which directly test the major hypotheses in this study and also includes several additional covariates to isolate the effect of education on civic participation. If the gap between those with a college background and those without college experience does not change, this supports the absolute education hypothesis. If the gap for competitive civic acts between those with college experience and those without a college background decreases, this supports the relative education hypothesis. And if the gap between those with college experience and those without any college background narrows for both competitive and non-competitive civic acts, this supports the selection effects hypothesis.

The relationship between education and civic engagement is statistically significant and substantively large across all six dependent variables and all three levels of education, suggesting that the relationship between education and civic participation does not degrade completely as cohort-level education increases. However, there is also a strong negative relationship between cohort-level education and civic acts for college-educated individuals. This is represented by the interaction terms between cohort- and region-specific educational attainment and the respondent's own educational levels.

\section{TABLE 3 HERE}


The interactions between educational level and cohort-level educational attainment are statistically significant; as the number of people earning four-year degrees goes up, the gap between those with a college background and those without a college background shrinks ${ }^{\mathrm{x}}$. However, the F-test results are statistically significant in five of the six models, indicating that there are cohort trends independent of the increase in degree attainment. To examine the narrowing civic gap in the context of other cohort-level changes and to assess the substantive significance of education over cohorts, Figure 4 shows the predicted probability for each educational level and plots the results across cohorts ${ }^{\mathrm{xi}}$.

Although the gap between college-educated and non-college educated individuals shrinks over cohorts in all six graphs, some of the changes are not substantively large compared to the overall cohort trends. For example, in the 1921-1925 birth cohort, a person with a four-year degree has a 0.0791 probability of writing a letter to the newspaper compared to 0.024 for a person with no college experience. By the 1966-1970 birth cohort, the predicted probabilities have hardly changed; 0.074 for an individual with a four year degree, and 0.0345 for an individual with no college experience. Petition signing also shows a similar trend. Thus, even though the interactions between respondent education and cohort-level education are statistically significant, they are small compared to overall cohort-level trends. This provides support for the absolute education model, as an increase in college education across the population does not substantially erode the distance between those who earn a higher degree and those who do not. FIGURE 4 HERE

However, the gap in contacting public officials, being part of a group devoted to promoting better government, and holding an organizational leadership position shrinks as the proportion of individuals with a college degree increases. For example, the predicted probability 
of contacting public officials and being part of a group devoted to promoting better government declines over cohorts for all levels of education, but the drop is much steeper for those who have had more college experience. A person in the 1921-1925 birth cohort with a four-year degree has a 0.2529 probability of contacting a congressperson or senator, compared to 0.1114 for a person with no college experience. The difference between the two groups is 0.1415 , but by the $1966-$ 1970 birth cohort the gap narrows to 0.0596 . This is strong evidence in favor of the relative education hypothesis—as the number of people in a birth cohort who have a college degree rises, the distance between those with a higher education and those who do not have college experience shrinks. The gaps in civic participation between those with a graduate degree and those with only a four-year degree also narrow, suggesting that the gaps narrow at the top of the educational spectrum as well ${ }^{\mathrm{xii}}$.

Furthermore, the educational gap in attending public meetings does not change much through the early baby boom, but narrows quickly afterwards. The gap in predicted probability between those with a four-year degree and those without any college background is 0.0779 in the 1921-1925 birth cohort, 0.0641 in the 1946-1950 birth cohort, and 0.0457 in the 1966-1970 birth cohort. Thus, there is almost no drop from 1921-1925 to 1946-1950, but a 28.77\% drop from 1946-1950 to the 1966-1970 cohort—a series of cohorts that also includes a major increase in educational attainment.

Because the gap between those with a college degree and those without a college degree declines as the amount of education increases, the present set of models primarily support the relative educational hypothesis. The educational gap in contacting public officials, being part of a group devoted to promoting better government, holding an organizational leadership position, and attending public meetings diminishes as cohorts become better educated. However, the 
absolute educational hypothesis also receives some support, as there is very little cohort-level change in the educational gap for signing a petition or writing a letter to the editor when compared to the overall cohort-level trends.

\section{Discussion}

In this study, I present three different pieces of evidence to test the changing relationship between educational attainment and civic participation. First, I show the overall cohort-level trends in civic participation using a basic Age-Period-Cohort model. Although the present results support Putnam's assertion (2000) that civic engagement is declining over cohorts, the cohorts born immediately after World War II have the highest rates of civic participation (which is similar to Caren, Ghoshal, and Ribas 2011). Second, I test how the relationship between educational attainment and civic participation changes as the higher education system expands; this model also includes several additional covariates, some of which are allowed to vary randomly by period or cohort when suggested by prior theory. As more cohort members complete college, the impact of educational attainment on civic engagement decreases for all six civic acts. However, while the educational gap for non-competitive civic acts does narrow over cohorts, this change is substantively small compared to the overall cohort-level trends. In comparison, the changing educational gaps in competitive civic acts are substantively significant. This is most consistent with the relative education hypothesis, which suggests that the probability of engaging in civic acts declines among those with a college degree compared to those without a college degree among competitive civic acts. Meanwhile, the absolute education hypothesis would predict that the educational gap would remain the same regardless of educational cohort changes, and the selection hypothesis would predict that the educational gap should narrow for all civic acts. 
Given the strong support for the relative education hypothesis, it is appealing to conclude that patterns of civic engagement are becoming more equitable. But while the education gap for civic engagement falls considerably over more recent cohorts, the overall rates for civic engagement also decline over cohorts ${ }^{\mathrm{xiii}}$. This is true, to a certain extent, for all forms of civic participation investigated in this paper. Figure 4 shows that in most cases, the shrinking gap comes from fewer college-educated individuals performing civic engagement rather than from an increase in non-college educated individuals; the only exception is writing a letter to the newspaper. Thus, while the relative education hypothesis is supported, claims to equity are tempered by the loss of civic participation across America as a whole.

The present findings provide further insight as to when the effects of a college education are absolute, and when they are relative to the educational level of their cohort. Education's impact on holding a leadership position in a local organization is contingent on the educational level of others in a cohort, and it is probable that this is due to competition. Individuals with college degrees usually have more human, social, and cultural capital (Putnam 2000; Stevens, Armstrong, and Arum 2008); all of these can be used to convince others to support their leadership intentions. However, if everyone in a person's cohort has the same levels of human, social, and cultural capital, then it no longer provides a competitive advantage (Campbell 2009; Nie, Junn, and Stehlik-Barry 1996). With the mass increase in college degree attendance and completion, there is much more competition than in the past.

The declining impact of education on contacting public officials and attending public meetings is not as easy to interpret. Obtaining a leadership position is competitive because only one person can hold it at a time, but contacting a public official is only competitive because an office can only receive a limited number of phone calls in a day, and attending a public meeting 
is only competitive if there is no physical space left for prospective attendees to sit or stand. However, it is probable that there is a declining ability of college attendees to make their voices heard, and that the relationship between education and civic participation is potentially mediated by the type of job a person has. In earlier eras, a person who graduated from college was likely to find a job that was secure and paid well (Kalleberg 2011). This would give the college attendee the resources that he or she needed to keep up with policy and to express their opinion: The ability to take time off of work without fear of being laid off, and the ability to make ends meet without taking on additional work. But the number of individuals with a college degree has increased, even as the number of secure and well-paid jobs has not (Kalleberg 2011). With more college-educated individuals and high job insecurity, a college graduate entering the job market in the 1980s (e.g., the 1956-1960 birth cohort) would face extremely stiff competition to obtain a stable job. In other words, the "competition” to participate in civic engagement may actually occur in the labor market rather than at the town hall (see also: Vaisey 2006). Given that entering the labor market during times of economic stress has the potential to stunt careers for the remainder of the life course (Elder 1999; Shanahan, Elder, and Miech 1997), it is not surprising that an entire cohort may have fewer resources to participate in civic life. Although the decline in work quality also affected individuals who had a high school education or less, they also had fewer resources to lose.

In contrast, petition signing is not a competitive activity. One person signing a petition does not make another person less likely to sign a petition, as the purpose of a petition is to gain as many signatures as possible. Furthermore, petition signing is a low-cost activity. Contacting a federal official or attending a public meeting requires the time to learn about issues and to craft a coherent statement; signing a petition only requires an appeal to sign. Thus, the impact of a 
college education on petition signing should not change as a function of either job quality or competition. The fact that education's impact on petition signing stays fairly constant over time supports the absolute education hypothesis (Campbell 2009).

There is one other way to explain the declining impact of education on contacting federal officials, attending public meetings, and obtaining leadership positions: The initial relationship between education and civic participation could be spurious, since family background and prior experiences affect both college attendance and civic engagement (Gibson 2001; Schnittker and Behrman 2012). In the earlier cohorts, the relationships between family background, adolescent experiences, and college attendance are relatively strong. But the sorts of people who aspire to higher education in more recent cohorts are now more likely to come from disadvantaged backgrounds (Goyette 2008), weakening the relationship between class status and educational attainment. Because of the new emphasis on sending more students to college (Rosenbaum 2001), the pool of college students increasingly consists of more people who have fewer resources and who may be less civically inclined. However, the selection effect hypothesis is unable to explain the trends in either petition signing or writing letters to newspapers. While the education gap for petition signing narrows over time it is not substantively significant compared to the overall cohort trends, and there is actually a marginal increase in writing letters to the editor among individuals with no college experience. The selection effect hypothesis predicts a decline in all forms of civic participation; thus, future research should investigate whether selection effects may operate for some types of civic engagement but not others.

Finally, the declining impact of education on membership in a group devoted to better government could be due to indirect competition via job quality, but it is also possible that it is due to the fact that there are very few groups devoted to better government left. While the other 
forms of civic participation exist in many different contexts, membership in a group devoted to promoting better government is dependent upon the existence of a specific type of organization. As groups devoted to promoting better government cease to exist, younger well-educated individuals cannot participate in these organizations. However, there is not any decline in participation among people with a high school degree or less, because they almost never participated in these groups in the first place (Wray-Lake and Hart 2012).

The present results challenge the conventional wisdom in sociology, which is that educational stratification has slowly replaced stratification based upon sex and race (Fischer and Hout 2006). There are three possible reasons why this study found a declining effect of education on social outcomes, while other studies do not. First, civic participation is an unusual life domain which is seen as "optional" by many individuals. Earning money and maintaining health are essential to survival, and thus it is possible that well-educated individuals are more willing to cut back on civic life than essential activities. Alternatively, it is possible that this study was able to identify a cohort-level decline in education because it tests for this in an age-period-cohort framework. Period trends can mask cohort-level trends, and other studies tend not to differentiate between cohort and period effects. However, the most likely reason for this study's different conclusion is that relative education is rarely tested outside of the civic participation literature. Applying the methodology described in this study to other areas could help establish whether the relative education hypothesis occurs in other life domains such as work and family.

The present study has two significant limitations, both of which are related to the Roper Social and Political Trends data. The primary value of this dataset is that it spans a substantial number of years and is extremely large, which makes it possible to estimate an age-period-cohort (APC) model of rare events. APC models are computationally intensive, and it is very difficult 
to achieve stable results when measuring low-base rate activities with medium-sized datasets. However, the present data only extends through 1994, with the final cohort born between 1971 and 1975. But the more significant limitation of this study is that I am unable to directly test for indirect competition (via job characteristics) and selection effects. If the Roper dataset included detailed occupational characteristics, this study could include analyses to determine whether job characteristics mediate the changing relationship between education and civic participation. Furthermore, details on family background — such as parental social class-would permit this study to control for the likelihood of attending college. The present results are consistent with indirect competition, but future studies should use datasets that can explicitly test whether job characteristics or selection effects explain cohort-level change.

\section{Conclusion}

This study investigates the relationship between education and civic participation, and whether that relationship has declined over time. Cohort-level increases in education do not affect less-intensive forms of civic participation, such as petition signing. However, as the proportion of college-educated individuals increased in each cohort, the relationship between individual educational attainment and civic participation declines. Although it is not possible to entirely rule out selection effects based on the available evidence, this study suggests that the relative education hypothesis best explains the relationship between education and civic life in competitive circumstances. On the other hand, non-competitive situations are best explained by the absolute education hypothesis.

Rosenbaum (2001) argues that social science researchers have not fully examined the consequences of the college-for-all movement on individual outcomes. Education has an impact on nearly every single life outcome, generally leading to more favorable results (Converse 1972; 
Hout 2012; Kingston et al. 2003). It is tempting to treat education's effects as time-invariant, and research on returns to education can be summarized by Hout's (2012, 394) accurate but somewhat simplified argument: "Education makes life better.” In contrast, this study helps demonstrate how education matters for different types of activities, using civic participation as the specific case. Is the relative education hypothesis true across other outcomes like income, health, or social resources? It is possible that education's effects on an individual are more contingent on cohort-level educational attainment than the prior literature suggests. Future studies should explicitly examine whether a similar pattern occurs for different individual-level outcomes, particularly outcomes connected to the labor market.

However, this study also undermines one of the key implications of the absolute education hypothesis: If education improves outcomes for each individual, then more education for the entire population should improve outcomes for everyone. But while encouraging a single person to go to college may empower that person in a competitive environment, encouraging an entire population to go to college does not empower the population in the same way. The population is subject to a limited set of opportunities and resources; education can help individuals obtain those opportunities and resources, but may not increase the total rewards available. As a result, the proper solution is changing the infrastructure that provides opportunities and resources; in the absence of structural change, the population will continue to “do less with more.” 


\section{References}

Jonathan Horowitz is a PhD candidate at the University of North Carolina-Chapel Hill. His research interests include life course sociology, social movements, the sociology of work, social psychology, social stratification, and the sociology of higher education. 


\section{References}

Brady, Henry E., Robert D. Putnam, Andrea L. Campbell, Laurel Elms, Steven Yonish, and Dorie Apollonio. 2000. Roper Social and Political Trends Data, 1973-1994. edited by the Roper Organization. Storrs, CT: Roper Center for Public Opinion Research, University of Connecticut.

Brand, Jennie E. 2010. "Civic Returns to Higher Education: A Note on Heterogeneous Effects." Social Forces no. 89 (2):417-433. doi: 10.1353/sof.2010.0095.

Brand, Jennie E., and Sarah A. Burgard. 2008. "Job Displacement and Social Participation over the Lifecourse: Findings for a Cohort of Joiners." Social Forces no. 87 (1):211-242.

Campbell, David E. 2009. "Civic Engagement and Education: An Empirical Test of the Sorting Model." American Journal of Political Science no. 53 (4):771-786.

Caren, Neal, Raj A. Ghoshal, and Vanesa Ribas. 2011. "A Social Movement Generation: Cohort and Period Trends in Protest Attendance and Petition Signing." American Sociological Review no. 76 (1):125-151. doi: 10.1177/0003122410395369.

Choi, Lona H. 2003. "Factors Affecting Volunteerism Among Older Adults." Journal of Applied Gerontology no. 22 (2):179-196. doi: 10.1177/0733464803022002001.

Converse, Philip E. 1972. "Change in the American Electorate." In The Human Meaning of Social Change, edited by Angus Campbell and P.E. Converse, 263-337. New York, NY: Russell Sage Foundation.

Elder, Glen H. 1999. Children of the Great Depression : social change in life experience. 25th anniversary ed. Boulder, CO: Westview Press.

Fischer, Claude S., and Michael Hout. 2006. Century of Difference: How America Changed in the Last One Hundred Years: Russell Sage Foundation Publications. 
Frenk, Steven M., Y. Claire Yang, and Kenneth C. Land. 2013. "Assessing the Significance of Cohort and Period Effects in Hierarchical Age-Period-Cohort Models: Applications to Verbal Test Scores and Voter Turnout in U.S. Presidential Elections." Social Forces no. 92 (1):221-248. doi: 10.1093/sf/sot066.

Gibson, John. 2001. "Unobservable family effects and the apparent external benefits of education." Economics of Education Review no. 20 (3):225-233. doi: 10.1016/s02727757(00)00020-0.

Glenn, Norval D. 2003. "Distinguishing Age, Period, and Cohort effects." In Handbook of the Life Course, edited by Jeylan T. Mortimer and Michael J. Shanahan, 465-476. New York, NY: Springer Science.

Goldin, Claudia D., and Lawrence F. Katz. 2008. The Race between Education and Technology. Cambridge, MA: Belknap Press.

Gomez, Rafael, and Morley Gunderson. 2003. "Volunteer Activity and the Demands of Work and Family." Relations Industrielles-Industrial Relations no. 58 (4):573-589.

Goyette, Kimberly A. 2008. "College for Some to College for All: Social Background, Occupational Expectations, and Educational Expectations Over Time." Social Science Research no. 37 (2):461-484. doi: 10.1016/j.ssresearch.2008.02.002.

Helliwell, John F., and Robert D. Putnam. 2007. "Education and Social Capital." Eastern Economic Journal no. 33 (1).

Henderson, John, and Sara Chatfield. 2011. "Who Matches? Propensity Scores and Bias in the Causal Effects of Education on Participation." Journal of Politics no. 73 (3):646-658. doi: $10.1017 / \mathrm{s} 0022381611000351$. 
Hout, Michael. 2012. "Social and Economic Returns to College Education in the United States." Annual Review of Sociology no. 38 (1):379-400. doi: doi:10.1146/annurev.soc.012809.102503.

Huang, J., H. M. van den Brink, and W. Groot. 2009. "A meta-analysis of the effect of education on social capital." Economics of Education Review no. 28 (4):454-464. doi: 10.1016/j.econedurev.2008.03.004.

Huang, Jian, Henriëtte Maassen van den Brink, and Wim Groot. 2009. "A meta-analysis of the effect of education on social capital." Economics of Education Review no. 28 (4):454464. doi: http://dx.doi.org/10.1016/j.econedurev.2008.03.004.

Kalleberg, Arne L. 2011. Good jobs, bad jobs: The rise of polarized and precarious employment systems in the United States, 1970s-2000s: Russell Sage Foundation.

Kam, Cindy D., and Carl L. Palmer. 2008. "Reconsidering the Effects of Education on Political Participation." The Journal of Politics no. 70 (3):612-631. doi: 10.2307/30219441.

Kaskie, Brian, Sara Imhof, Joseph Cavanaugh, and Kennith Culp. 2008. "Civic Engagement as a Retirement Role for Aging Americans." Gerontologist no. 48 (3):368-377.

Kerrissey, Jasmine, and Evan Schofer. 2013. "Union Membership and Political Participation in the United States." Social Forces no. 91 (3):895-928. doi: 10.1093/sf/sos187.

King, Miriam, Steven Ruggles, J. Trent Alexander, Sarah Flood, Katie Genadek, Matthew B. Schroeder, Brandon Trampe, and Rebecca Vick. 2010. Current Population Survey: Version 3.0. Minneapolis: University of Minnesota.

Kingston, Paul W., Ryan Hubbard, Brent Lapp, Paul Schroeder, and Julia Wilson. 2003. "Why Education Matters." Sociology of Education no. 76 (1):53-70. doi: 10.2307/3090261. 
Lee, Young joo, and Jeffrey L. Brudney. 2009. "Rational volunteering: a benefit-cost approach." International Journal of Sociology and Social Policy no. 29 (9/10):512-530. doi: doi:10.1108/01443330910986298.

Lim, Chaeyoon, and Thomas Sander. 2013. "Does misery love company? Civic engagement in economic hard times." Social Science Research no. 42 (1):14-30. doi: http://dx.doi.org/10.1016/j.ssresearch.2012.07.004.

Mason, Karen O., William M. Mason, Halliman H. Winsborough, and W. Kenneth Poole. 1973. "Some Methodological Issues in Cohort Analysis of Archival Data." American Sociological Review:242-258.

Mayer, Alexander K. 2011. "Does Education Increase Political Participation?" Journal of Politics no. 73 (3):633-645. doi: 10.1017/s002238161100034x.

McBride, Amanda Moore, Ernest Gonzales, Nancy Morrow-Howell, and Stacey McCrary. 2011. "Stipends in Volunteer Civic Service: Inclusion, Retention, and Volunteer Benefits." Public Administration Review no. 71 (6):850-858. doi: 10.1111/j.15406210.2011.02419.x.

Meyer, David S., and Sidney Tarrow. 1998. "A Movement Society: Contentious Politics for a New Century." In The Social Movement Society: Contentious Politics for a New Century, edited by David S. Meyer and Sidney Tarrow, 1-28. Lanham, MD: Rowman \& Littlefield.

Moffatt, Michael. 1989. Coming of age in New Jersey: College and American culture. New Brunswick, NJ: Rutgers University Press.

Musick, Marc A, and John Wilson. 2007. Volunteers: A social profile. Bloomington, IN: Indiana University Press. 
Nie, Norman H., Jane Junn, and Kenneth Stehlik-Barry. 1996. Education and Democratic Citizenship in America: University of Chicago Press.

Oesterle, S., M. K. Johnson, and J. T. Mortimer. 2004. "Volunteerism during the transition to adulthood: A life course perspective." Social Forces no. 82 (3):1123-1149. doi: 10.1353/sof.2004.0049.

Pallas, Aaron M. 2006. "The Effects of Schooling on Individual Lives." In Handbook of the Sociology of Education, edited by Maureen T. Hallinan, 499-525. Springer US.

Price, Bob. 2002. "Social capital and factors affecting civic engagement as reported by leaders of voluntary associations." The Social Science Journal no. 39 (1):119-127. doi: http://dx.doi.org/10.1016/S0362-3319(01)00169-0.

Putnam, Robert D. 1995. "Tuning In, Tuning Out - The Strange Disappearance of Social Capital in America." Political Science \& Politics no. 28 (4):664-683. doi: 10.2307/420517.

- 2000. Bowling Alone: The Collapse and Revival of American Community. New York, NY: Simon \& Schuster.

Riley, Matilda White. 1987. "On the Significance of Age in Sociology." American Sociological Review no. 52 (1):1-14.

Rosenbaum, James E. 2001. Beyond college for all : career paths for the forgotten half, American Sociological Association's Rose series in sociology. New York: Russell Sage Foundation.

Rotolo, Thomas. 2000. "A Time to Join, a Time to Quit: The Influence of Life Cycle Transitions on Voluntary Association Membership." Social Forces no. 78 (3):1133-1161. doi: $10.2307 / 3005944$. 
Rotolo, Thomas, and John Wilson. 2003. "Work Histories and Voluntary Association Memberships." Sociological Forum no. 18 (4):603-619. doi: 10.2307/3648914.

— 2006. "Substitute or complement? Spousal influence on volunteering." Journal of Marriage and Family no. 68 (2):305-319. doi: 10.1111/j.1741-3737.2006.00254.x.

Schnittker, Jason, and Jere R. Behrman. 2012. "Learning to do well or learning to do good? Estimating the effects of schooling on civic engagement, social cohesion, and labor market outcomes in the presence of endowments." Social Science Research no. 41 (2):306-320. doi: 10.1016/j.ssresearch.2011.11.010.

Shanahan, Michael J., Glen H. Elder, and Richard A. Miech. 1997. "History and agency in men's lives: Pathways to achievement in cohort perspective." Sociology of Education no. 70 (1):54-67. doi: 10.2307/2673192.

Skoric, Marko M., Deborah Ying, and Ying Ng. 2009. "Bowling Online, Not Alone: Online Social Capital and Political Participation in Singapore." Journal of Computer-Mediated Communication no. 14 (2):414-433. doi: 10.1111/j.1083-6101.2009.01447.x.

Smets, Kaat, and Anja Neundorf. 2014. "The hierarchies of age-period-cohort research: Political context and the development of generational turnout patterns." Electoral Studies no. 33 (0):41-51. doi: http://dx.doi.org/10.1016/j.electstud.2013.06.009.

Snyder, Thomas D., and Sally A. Dillow. 2010. Digest of Education Statistics, 2009. edited by Institute of Education Sciences National Center for Education Statistics, U.S. Department of Education. Washington DC.

Stevens, Mitchell L., Elizabeth A. Armstrong, and Richard Arum. 2008. "Sieve, Incubator, Temple, Hub: Empirical and Theoretical Advances in the Sociology of Higher 
Education." Annual Review of Sociology no. 34 (1):127-151. doi:

doi:10.1146/annurev.soc.34.040507.134737.

Stoker, Laura, and M. Kent Jennings. 1995. "Life-Cycle Transitions and Political Participation: The Case of Marriage." The American Political Science Review no. 89 (2):421-433. doi: $10.2307 / 2082435$.

Tenn, Steven. 2005. "An Alternative Measure of Relative Education to Explain Voter Turnout." Journal of Politics no. 67 (1):271-282.

Vaisey, Stephen. 2006. "Education and its discontents: Overqualification in America, 19722002." Social Forces no. 85 (2):835-864. doi: 10.1353/sof.2007.0028.

Verba, Sidney, Kay Lehman Schlozman, and Henry E. Brady. 1995. Voice and equality: Civic voluntarism in American politics. Cambridge, MA: Harvard University Press.

Wilensky, Harold L. 1961. "Orderly Careers and Social Participation: The Impact of Work History on Social Integration in the Middle Mass." American Sociological Review no. 26 (4):521-539. doi: 10.2307/2090251.

Wilson, John, and Marc Musick. 1997. "Work and volunteering: The long arm of the job." Social Forces no. 76 (1):251-272. doi: 10.2307/2580325.

Wray-Lake, Laura, and Daniel Hart. 2012. "Growing Social Inequalities in Youth Civic Engagement? Evidence from the National Election Study." Ps-Political Science \& Politics no. 45 (3):456-461. doi: 10.1017/s1049096512000339.

Yang, Yang. 2006. "A Mixed Models Approach to the Age-Period-Cohort Analysis of Repeated Cross-Section Surveys, with an Application to Data on Trends in Verbal Test Scores." Sociological Methodology no. 36 (1):75-97. doi: 10.1111/j.1467-9531.2006.00175.x. 
— 2008. "Social inequalities in happiness in the United States, 1972 to 2004: An ageperiod-cohort analysis." American Sociological Review no. 73 (2):204-226. doi: 10.1177/000312240807300202.

— 2010. "Aging, Cohorts, and Methods." In Handbook of Aging and Social Sciences, edited by Robert H. Binstock and Linda K. George, 17-30. San Diego, CA: Academic Press.

Yang, Yang, and Kenneth C. Land. 2008. "Age-Period-Cohort Analysis of Repeated CrossSection Surveys: Fixed or Random Effects?" Sociological Methods \& Research no. 36 (3):297-326. doi: 10.1177/0049124106292360.

Zullo, Roland. 2013. "Organized Labor's Civic Niche." Nonprofit and Voluntary Sector Quarterly no. 42 (4):781-802. doi: 10.1177/0899764012450534. 
$\underline{\text { Table 1. Descriptive Statistics }}$

\begin{tabular}{|c|c|c|}
\hline & Proportion & $\sigma$ \\
\hline \multicolumn{3}{|l|}{$\underline{\text { Independent Variables }}$} \\
\hline Age: $25-29$ & 0.1262 & 0.3321 \\
\hline Age: $30-34$ & 0.1142 & 0.3180 \\
\hline Age: 35-39 & 0.0939 & 0.2917 \\
\hline Age: 40-44 (Ref) & 0.0883 & 0.2837 \\
\hline Age: $45-49$ & 0.0816 & 0.2738 \\
\hline Age: $50-54$ & 0.0624 & 0.2419 \\
\hline Age: 55-59 & 0.0682 & 0.2520 \\
\hline Age: 60-64 & 0.0709 & 0.2566 \\
\hline Female (1=Yes) & 0.5278 & 0.4992 \\
\hline White (Ref) & 0.8626 & 0.3443 \\
\hline Black (1=Yes) & 0.1142 & 0.3181 \\
\hline Other Race (1=Yes) & 0.0261 & 0.1956 \\
\hline Hispanic (1=Yes) & 0.0550 & 0.2280 \\
\hline Married (1=Yes) & 0.6435 & 0.4790 \\
\hline Kids 12 and Under ( $1=$ Yes) & 0.3429 & 0.4747 \\
\hline Kids Over 12 (1=Yes) & 0.1889 & 0.3914 \\
\hline Full-Time Employee (Ref) & 0.4802 & 0.4996 \\
\hline Part-Time Employee & 0.1151 & 0.3192 \\
\hline Retired & 0.1437 & 0.3508 \\
\hline Unemployed & 0.0443 & 0.2058 \\
\hline Homemaker & 0.1730 & 0.3782 \\
\hline Other Not Working & 0.0433 & 0.2036 \\
\hline Union Member & 0.3248 & 0.6464 \\
\hline Lives in Political South & 0.2408 & 0.4276 \\
\hline No College Degree & 0.6009 & 0.4897 \\
\hline Some College/2 Year Degree & 0.2157 & 0.4113 \\
\hline 4 Year Degree & 0.1185 & 0.3232 \\
\hline More than 4 Year Degree & 0.0649 & 0.2464 \\
\hline \multicolumn{3}{|l|}{ Dependent Variables } \\
\hline Contacted Federal Official & 0.1450 & 0.3521 \\
\hline Wrote Letter to Paper & 0.0499 & 0.2178 \\
\hline Had Org. Leadership Position & 0.1328 & 0.3393 \\
\hline Signed Petition & 0.3423 & 0.4745 \\
\hline Attended Public Meeting & 0.1757 & 0.3806 \\
\hline Member of Group Promoting Better Govt. & 0.0358 & 0.1857 \\
\hline
\end{tabular}


Table 2. Model 1: Age, Period, and Cohort Trends

\begin{tabular}{|c|c|c|c|c|c|c|}
\hline & $\begin{array}{c}\text { Contacted } \\
\text { Official }\end{array}$ & $\begin{array}{l}\text { Letter to } \\
\text { Paper }\end{array}$ & $\begin{array}{l}\text { Served in } \\
\text { Organization }\end{array}$ & $\begin{array}{l}\text { Signed a } \\
\text { Petition }\end{array}$ & $\begin{array}{c}\text { Attended } \\
\text { Public Meeting }\end{array}$ & $\begin{array}{c}\text { Member of } \\
\text { Grp. Promoting } \\
\text { Better Govt. }\end{array}$ \\
\hline \multicolumn{7}{|l|}{ Coefficients } \\
\hline \multirow[t]{2}{*}{ Age: $25-29$} & $.1321^{* * *}$ & -.03382 & -.02962 & $.1255^{* * *}$ & $.115^{* * *}$ & $.1187^{* *}$ \\
\hline & $(.02186)$ & $(.03138)$ & $(.02132)$ & $(.01392)$ & $(.01827)$ & $(.03949)$ \\
\hline \multirow[t]{2}{*}{ Age: $30-34$} & $.1955^{* * *}$ & $.1182 * * *$ & $.1632 * * *$ & $.1866 * * *$ & $.3624 * * *$ & $.1466 * * *$ \\
\hline & $(.02123)$ & $(.03104)$ & $(.02077)$ & $(.01459)$ & $(.01783)$ & $(.03909)$ \\
\hline \multirow[t]{2}{*}{ Age: 35-39 } & $.2345^{* * *}$ & $.1544^{* * *}$ & $.3114^{* * *}$ & $.2267 * * *$ & $.4654^{* * *}$ & $.2153^{* * *}$ \\
\hline & $(.02108)$ & $(.03209)$ & $(.02066)$ & $(.01543)$ & $(.01807)$ & $(.03888)$ \\
\hline \multirow[t]{2}{*}{ Age: $45-49$} & $.08904 * * *$ & $.1383 * * *$ & $.066^{* *}$ & $.1494^{* * *}$ & $.09883 * * *$ & $.09337^{*}$ \\
\hline & $(.02252)$ & $(.03618)$ & $(.02326)$ & $(.01723)$ & $(.02097)$ & $(.04242)$ \\
\hline \multirow[t]{2}{*}{ Age: $50-54$} & $.1044^{* * *}$ & $.1502 * * *$ & $.06122^{*}$ & $.1802^{* * *}$ & .00159 & $.1405^{* *}$ \\
\hline & $(.02487)$ & $(.0415)$ & $(.02661)$ & $(.01943)$ & $(.02492)$ & $(.04722)$ \\
\hline \multirow[t]{2}{*}{ Age: 55-59 } & $.1342 * * *$ & $.1945^{* * *}$ & $.06845^{* *}$ & $.1723^{* * *}$ & .01309 & $.139 * *$ \\
\hline & $(.0231)$ & $(.03994)$ & $(.02597)$ & $(.01866)$ & $(.02529)$ & $(.04449)$ \\
\hline \multirow[t]{2}{*}{ Age: $60-64$} & $.04551^{*}$ & $.08601 *$ & -.00341 & $.1959 * * *$ & .01788 & .02985 \\
\hline & $(.02217)$ & $(.04011)$ & $(.02608)$ & $(.01807)$ & $(.02587)$ & $(.04369)$ \\
\hline \multirow[t]{2}{*}{ Intercept } & $-1.957^{* * *}$ & $-3.0934 * * *$ & $-2.105^{* * *}$ & $-.8839 * * *$ & $-1.8898 * * *$ & $-3.4433 * * *$ \\
\hline & $(.1131)$ & $(.05167)$ & $(.1098)$ & $(.0924)$ & $(.1308)$ & $(.06998)$ \\
\hline \multicolumn{7}{|l|}{ Variance Components } \\
\hline \multirow[t]{2}{*}{ Period (Intercept) } & 0.04542 & 0.002467 & 0.03473 & 0.02117 & 0.02217 & 0.002956 \\
\hline & $(0.002983)$ & $(0.1037)$ & $(0.02219)$ & $(0.01348)$ & $(0.01419)$ & $(0.002295)$ \\
\hline \multirow[t]{2}{*}{ Cohort (Intercept) } & $0.1554 * *$ & $0.02645^{*}$ & $0.08020 * *$ & $0.06453 * *$ & $0.1732 * *$ & $0.05323 * *$ \\
\hline & $(0.06394)$ & $(0.01162)$ & $(0.03322)$ & $(0.02655)$ & $(0.07116)$ & $(0.0107)$ \\
\hline -2 Residual Log Pseudo-Likelihood & 1594488 & 1892162 & 1622416 & 1393452 & 1559531 & 1997473 \\
\hline $\mathrm{N}$ & 319152 & 319152 & 319152 & 319152 & 319152 & 319152 \\
\hline
\end{tabular}


Standard Errors are in Parentheses.

$* * * p<0.001, * * p<0.01, * p<0.05$ 
Table 3. Model 2: Age, Period, Cohort, Educational Information and Control Variables

\begin{tabular}{|c|c|c|c|c|c|c|}
\hline & $\begin{array}{c}\text { Contacted } \\
\text { Official }\end{array}$ & $\begin{array}{l}\text { Letter to } \\
\text { Paper }\end{array}$ & $\begin{array}{c}\text { Served in } \\
\text { Organization } \\
\end{array}$ & $\begin{array}{l}\text { Signed a } \\
\text { Petition } \\
\end{array}$ & $\begin{array}{c}\text { Attended Public } \\
\text { Meeting }\end{array}$ & $\begin{array}{c}\text { Member of } \\
\text { Grp. Promoting } \\
\text { Better Govt. }\end{array}$ \\
\hline \multicolumn{7}{|l|}{ Coefficients } \\
\hline \multirow[t]{2}{*}{ Age: $25-29$} & .04605 & $-.07938 *$ & $-.1018^{* * *}$ & .03261 & .0283 & .0407 \\
\hline & $(.02552)$ & $(.03582)$ & $(.02486)$ & $(.01665)$ & $(.02151)$ & $(.04509)$ \\
\hline \multirow[t]{2}{*}{ Age: $30-34$} & $.07944^{* *}$ & .05135 & .03817 & $.07177^{* * *}$ & $.1739 * * *$ & .0727 \\
\hline & $(.02504)$ & $(.03578)$ & $(.02443)$ & $(.01755)$ & $(.02103)$ & $(.04488)$ \\
\hline \multirow[t]{2}{*}{ Age: $35-39$} & $.0946^{* * *}$ & .06339 & $.1254^{* * *}$ & $.06291 * * *$ & $.1933^{* * *}$ & $.1142^{* *}$ \\
\hline & $(.02438)$ & $(.03608)$ & $(.02378)$ & $(.0182)$ & $(.02077)$ & $(.04388)$ \\
\hline \multirow[t]{2}{*}{ Age: $45-49$} & .02728 & $.1092 * *$ & -.02738 & .03974 & .001399 & -.001 \\
\hline & $(.02616)$ & $(.04007)$ & $(.02668)$ & $(.02042)$ & $(.0243)$ & $(.04825)$ \\
\hline \multirow[t]{2}{*}{ Age: 50-54 } & .03285 & $.1229 * *$ & -.03494 & $.0526 *$ & -.01526 & .072 \\
\hline & $(.02951)$ & $(.0468)$ & $(.03122)$ & $(.02347)$ & $(.02945)$ & $(.05454)$ \\
\hline \multirow[t]{2}{*}{ Age: 55-59 } & $.0648^{*}$ & $.149 * *$ & -.02167 & $.07922 * * *$ & .03084 & .0582 \\
\hline & $(.02808)$ & $(.04616)$ & $(.03109)$ & $(.02293)$ & $(.03034)$ & $(.05278)$ \\
\hline \multirow[t]{2}{*}{ Age: $60-64$} & -.02302 & .05354 & $-.09398 * *$ & $.1373 * * *$ & .01168 & -.0495 \\
\hline & $(.02633)$ & $(.04554)$ & $(.0307)$ & $(.02165)$ & $(.03044)$ & $(.0507)$ \\
\hline \multirow[t]{2}{*}{ Black } & $-.8855 * * *$ & $-.6225 * * *$ & $-.2726 * * *$ & $-.6601 * * *$ & $-.14^{* * *}$ & $.0831 *$ \\
\hline & $(.02787)$ & $(.04189)$ & $(.02411)$ & $(.01689)$ & $(.02002)$ & $(.0396)$ \\
\hline \multirow[t]{2}{*}{ Other } & $-.5897 * * *$ & $-.3584 * * *$ & $-.6373 * * *$ & $-.684^{* * *}$ & $-.5179 * * *$ & $-.315^{* * *}$ \\
\hline & $(.04921)$ & $(.06963)$ & $(.05084)$ & $(.03212)$ & $(.04076)$ & (.08399) \\
\hline \multirow[t]{2}{*}{ Hispanic } & $-.3471 * * *$ & $-.1876 * * *$ & $-.2091 * * *$ & $-.2198 * * *$ & $-.06099 *$ & -.0475 \\
\hline & $(.03461)$ & $(.05139)$ & $(.0344)$ & $(.0226)$ & $(.02798)$ & $(.06085)$ \\
\hline \multirow[t]{2}{*}{ Female } & $.07272 * * *$ & $-.06257 * *$ & $.07259 * * *$ & $.08579 * * *$ & $.1458^{* * *}$ & $.2597 * * *$ \\
\hline & $(.01308)$ & $(.02038)$ & $(.01365)$ & $(.009804)$ & $(.01233)$ & $(.02379)$ \\
\hline \multirow[t]{2}{*}{ Married } & $.1474^{*}$ & .053 & $.1471^{*}$ & $.1179 *$ & $.2118^{* *}$ & $-.1293^{*}$ \\
\hline & $(.0483)$ & $(.05269)$ & $(.05744)$ & $(.04505)$ & $(.05094)$ & $(.05246)$ \\
\hline \multirow[t]{2}{*}{ Kids 12 and Under } & $.06759 * * *$ & .007433 & $.1703 * * *$ & $.08502 * * *$ & $.5033 * * *$ & -.0024 \\
\hline & $(.01608)$ & $(.02431)$ & $(.01597)$ & $(.01166)$ & $(.01385)$ & $(.02924)$ \\
\hline Kids Over 12 & $.0457 * *$ & $.08951 * * *$ & $.2287 * * *$ & $.08021 * * *$ & $.4332 * * *$ & .0563 \\
\hline
\end{tabular}


Part-Time Employee

Retired

Unemployed

Homemaker

Not Working (Other)

Union Member

Income (Top Quartile)

Income (Bottom Quartile)

Some College or 2 Yr. Deg.

4 Year College Degree

More than 4 Year Degree

Proportion of 4 Year Deg.

Political South

Prop.*Some College

Prop. *4 Year Degree

Prop.*> 4 Year Deg.

Intercept

\begin{tabular}{|c|c|c|c|}
\hline$(.01638)$ & $(.02517)$ & $(.0161)$ & $(.01222)$ \\
\hline $.09924 * * *$ & $.1923 * * *$ & $.2621 * * *$ & $.07615^{* * *}$ \\
\hline$(.01912)$ & $(.0286)$ & $(.01897)$ & $(.01417)$ \\
\hline $.1286 * * *$ & $.1086^{* *}$ & -.01176 & -.02132 \\
\hline$(.0235)$ & $(.03875)$ & $(.02654)$ & $(.01912)$ \\
\hline$-.1342 * * *$ & -.06739 & $-.276 * * *$ & $-.1794 * * *$ \\
\hline$(.03674)$ & $(.05482)$ & $(.03942)$ & $(.02371)$ \\
\hline$-.1879 * * *$ & $-.06949 *$ & $-.08404 * * *$ & $-.2271 * * *$ \\
\hline$(.02052)$ & $(.03335)$ & $(.02103)$ & $(.01487)$ \\
\hline $.1251 * * *$ & $.2196 * * *$ & $.1167 * * *$ & -.00725 \\
\hline$(.0325)$ & $(.0458)$ & $(.03285)$ & $(.02306)$ \\
\hline $.1254 * * *$ & $.1068 * * *$ & $.05464 * * *$ & $.1286 * * *$ \\
\hline$(.00913)$ & $(.01422)$ & $(.009515)$ & $(.006908)$ \\
\hline $.1984 * * *$ & $.1158 * * *$ & $.2368 * * *$ & $.2077 * * *$ \\
\hline$(.01385)$ & $(.02142)$ & $(.01409)$ & $(.01076)$ \\
\hline$-.2646 * * *$ & $-.1365^{* * *}$ & $-.3646 * * *$ & $-.2983 * * *$ \\
\hline$(.0177)$ & $(.02829)$ & $(.01941)$ & $(.01237)$ \\
\hline $.9636 * * *$ & $1.1223^{* * *}$ & $1.1403 * * *$ & $.8001 * * *$ \\
\hline$(.04867)$ & $(.08217)$ & $(.054)$ & $(.03992)$ \\
\hline $1.0674 * * *$ & $1.52^{* * *}$ & $1.3218^{* * *}$ & $.8265^{* * *}$ \\
\hline$(.05798)$ & $(.09281)$ & $(.06241)$ & $(.05014)$ \\
\hline $1.5777^{* * *}$ & $1.9077^{* * *}$ & $1.8495^{* * *}$ & $1.2185^{* * *}$ \\
\hline$(.06591)$ & $(.09811)$ & $(.06898)$ & $(.06258)$ \\
\hline$-1.6596 * * *$ & $2.4158^{* * *}$ & -.4221 & .08111 \\
\hline$(.241)$ & $(.3384)$ & $(.237)$ & (.1711) \\
\hline-.1238 & -.07973 & -.0238 & $-.4165^{*}$ \\
\hline$(.05991)$ & $(.03482)$ & $(.04501)$ & (.1066) \\
\hline$-.6502 *$ & $-2.6979 * * *$ & $-1.3571 * * *$ & $-.499 *$ \\
\hline$(.2731)$ & $(.4257)$ & $(.2874)$ & $(.2254)$ \\
\hline$-1.0206 * * *$ & $-1.6391 * * *$ & $-1.735^{* * *}$ & $-.5656 * *$ \\
\hline$(.2355)$ & (.3789) & $(.2533)$ & $(.1826)$ \\
\hline-.5466 & $-2.437 * * *$ & $-1.3173 * * *$ & -.4956 \\
\hline$(.3108)$ & $(.4556)$ & (.3209) & $(.2874)$ \\
\hline$-2.0566 * * *$ & $-3.9864 * * *$ & $-2.6017 * * *$ & $-1.0479 * * *$ \\
\hline
\end{tabular}

(.03009) $.2062^{* * *}$

(.03347)

.0471

(.04437)

.0031

(.06582)

$-.1095 * *$

(.03863)

(.05951)

$.0761 * * *$

(.01703)

$.2637 * * *$

(.02503)

$-.2935^{* * *}$

(.03465)

$1.2322^{* * *}$

(.0945)

$1.5255^{* * *}$

(.1043)

2.2407***

(.1026)

$.9079 *$

(.4471)

$-.0451$

(.02892)

$-1.7482^{* * *}$

(.4931)

$-1.7224^{* * *}$

(.4536)

$-1.975^{* * *}$

(.4931)

$-4.2674 * * *$ 
$\begin{array}{llllll}(.08966) & (.08396) & (.09458) & (.09582) & (.09026)\end{array}$

Variance Components

Period (Intercept)

Period (Political South)

0.005919

(0.003915)

0.002850
$(0.002360)$

0.03271

(0.02107)

0.02635

(0.01683)

0.01599

$(0.01039)$

0.001731

0.2011

0.003852

0.01060

0.06737

0.02698

$(0.001613)$

(0.01393)

(0.004539)

(0.007901)

(0.04318)

(0.01791)

0.000557

Cohort (Intercept)

$0.05797^{* *}$

0.007376

$0.009809 *$

$0.04444^{*}$

$0.04127 *$

(0.002620)

(0.02488)

(0.04706)

(0.01939)

$(0.01858)$

$0.04441^{*}$

$0.02667 *$

$0.03872^{*}$

$0.02445^{*}$

$0.03013^{*}$

$(0.02367)$

(0.01341)

(0.01471)

(0.01775)

(0.01123)

(0.01415)

$0.02479 *$

$(0.01378)$

\begin{tabular}{l}
-2 Residual Log Pseudo-Likelihood \\
$\mathrm{N}$ \\
\hline Standard Errors are in Parentheses. \\
$* * * p<0.001,{ }^{* *} p<0.01, * p<0.05$
\end{tabular}

1326417
319152

1566787

1350196

1153515

1288990

1672559

319152

319152

319152

319152

319152

*** $p<0.001,{ }^{* *} p<0.01, * p<0.05$ 


\section{Endnotes}

${ }^{\mathrm{i}}$ This is especially valuable social capital because it involves connections to other well-educated individuals.

ii This suggests that education may not affect voting in the same way as other types of civic participation. It is possible that there is a relative education trend in voting behavior that is masked by period changes; however, the lack of a strong cohort effect suggests this is not the case. As a result, the findings in this study may not generalize to voting behavior. Further evidence suggesting that voting is not comparable to other forms of civic behavior comes from Wray-Lake and Hart (2012), who found that the gap between education and civic participation has actually increased over time.

iii That said, this issue is not particularly relevant to Putnam's argument, since his primary data source ends in 1994, before internet use dramatically increased in the mid-to-late 1990s. This study uses the same data source (the Roper Social and Political Trends), and so also is not particularly relevant to this study.

${ }^{\text {iv }}$ Many of these cohort-level variables are only available to a small subset of participants in the dataset used in this study. Fortunately, the Age-Period-Cohort modeling strategy employed here accounts for these additional trends in the cohort-level random intercept.

${ }^{\mathrm{v}}$ The other six activities-such as holding or running for political office-were so rare that it was not possible to estimate the separate effects of age, period, and cohort. Thus, I am also unable to report whether the impact of education on these activities changed over cohorts.

vi The question's wording is technically “congressman." However, I use "congressperson” to match the American Sociological Association's preferred publication style.

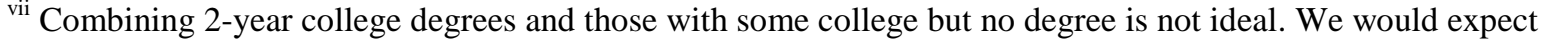
individuals who have some college to have higher levels of human, social, and cultural capital than those with a high school education, but they lack the educational credentials of a 2-year degree holder and therefore should fare worse in the labor market. Although the Roper data does not distinguish between these two groups, it is definitely preferable to separate them when possible. This is increasingly important when utilizing recent data (compared to Roper), as recent cohorts seem to have a higher proportion of individuals who enter college but do not earn a degree. viii In less technical terms: To create this measurement, I sub-divided the Current Population Survey into multiple different samples, one for each region by cohort combination. I then calculated the proportion of participants who had a four-year college degree in each.

ix The F-test is used to determine whether there are any differences across period and cohort; for more information about this test and the F-statistic in age-period cohort models, see Frenk, Yang, and Land (2013).

${ }^{\mathrm{x}}$ The negative relationship between the college background-relative education interaction and civic participation could be a rebound effect caused by a high correlation between the individual-level educational attainment measures and relative education. However, these correlations range between 0.0287 and 0.1299 , which is relatively low. Furthermore, removing the cohort- and region-educational level from the analysis does not alter the negative relationship between the college background-relative education interaction and civic participation.

${ }^{x i}$ To calculate the predicted probabilities, I use the time-invariant intercept $\left(\gamma_{00}\right)$, the cohort-specific intercept $\left(c_{0 k}\right)$, educational level $\left(\gamma_{60} ; \gamma_{70} ; \gamma_{80}\right)$, relative education $\left(\gamma_{01}\right)$, and the interaction between educational level and relative education $\left(\gamma_{61} ; \gamma_{71} ; \gamma_{81}\right)$. I set all other variables to the reference group $(\mathrm{X}=0)$, and use the overall proportion of individuals with a 4-year college degree in each cohort as the value for $X_{\text {college_proportion. }}$. So to calculate the predicted probability for those with a 4-Year Degree, I use the formula $\exp \left(\gamma_{00}+\gamma_{01}\left(X_{\text {cprop }}\right)+c_{0 k}+\gamma_{70}+\right.$ $\left.\gamma_{71}\left(X_{\text {cprop }}\right)\right) /\left(1+\exp \left(\gamma_{00}+\gamma_{01}\left(X_{\text {cprop }}\right)+c_{0 k}+\gamma_{70}+\gamma_{71}\left(X_{\text {cprop }}\right)\right)\right)$.

xii The relative education argument could be stronger if I could distinguish between those who have completed some graduate degree and those who have finished the degree; unfortunately the data does not permit that comparison.

xiii Putnam (2000) argues that the overall decline is due to declining informal social interaction and social trust among younger cohorts. This helps explain the overall decline, but not why it is declining faster among educated individuals. 